\title{
Significados, representaciones y lenguaje: las fracciones en tres generaciones de libros de texto para primaria
}

\author{
Meanings, representations and language: fractions in three \\ generations of textbooks for primary
}

\section{Alicia Avila ${ }^{1}$}

Resumen: En este artículo se presentan los resultados de una investigación documental cuyo objetivo fue poner de relieve los aspectos valiosos y las debilidades de tres propuestas curriculares para la enseñanza de las fracciones. El análisis se hace mediante identificación de los sub-constructos del número racional considerados en cada oportunidad, así como el tránsito entre el conocimiento informal (etnomatemático) y el técnico-simbólico identificados en los tres currículos y libros de texto oficiales utilizados entre 1960 y 2011 en la educación primaria mexicana. El acercamiento se sustenta, esencialmente, en la conceptualización de Thomas Kieren respecto de: a) los sub-constructos que constituyen un conocimiento cabal de las fracciones, y b) el trayecto deseable entre el conocimiento informal y el técnico-simbólico también sugerido por este investigador. Se considera que el trabajo aporta una metodología útil para analizar las propuestas curriculares y la enseñanza de estos números; también se pone de relieve que -al elaborar nuevos planteamientos educativos- es pertinente recuperar las lecciones del pasado si el interés no es la innovación sino la mejora de la enseñanza.

Fecha de recepción: 27 de marzo de 2018. Fecha de aceptación: 30 de junio de 2019.

1 Universidad Pedagógica Nacional. México. aliavi@prodigy.net.mx, orcid.org/0000-0003-0872-57xx 
Palabras clave: propuestas curriculares, enseñanza de las fracciones, historia de la enseñanza de las matemáticas, educación primaria.

\begin{abstract}
This article presents the results of a documentary research developed with the aim of highlighting valuable aspects and weaknesses of three curricular proposals for the teaching of fractions. The analysis is done by identifying the sub-constructs of the rational number considered in each opportunity, as well as the transition between informal (ethnomathematical) and technical-symbolic knowledge observed in the three official curricula and textbooks of the Mexican Primary Education used between 1960 and 2011. The approach is based, essentially, on the conceptualization of Thomas Kieren regarding: a) the sub-constructs that constitute a thorough knowledge of the fractions, and b) the desirable path between the informal knowledge and the technical-symbolic also suggested by this researcher. It is considered that the work provides a useful methodology to analyze the curricular proposals and the teaching of these numbers, it also highlights that it is pertinent to recover the lessons of the past if the interest is not innovation but the improvement of teaching.
\end{abstract}

Keywords: curricular proposals, teaching of fractions, history of mathematics teaching, primary education

\title{
INTRODUCCIÓN
}

¿Todavía es lícito interesarse en las fracciones?, se pregunta Athanasios Gagatsis al prologar el libro de Isabel Fandiño sobre estos números (Fandiño, 2009). Esta provocadora frase es seguida de una disquisición que concluye con la afirmación de que el libro de Fandiño es muestra de lo mucho que el estudio de las fracciones tiene aún por ofrecer a la comunidad de la educación matemática. Yo comparto la convicción de Gagatsis y es por ello que decidí escribir este artículo.

Las fracciones han sido uno de los contenidos de la educación primaria más estudiados por los investigadores de la educación matemática de este nivel. Ya en los años ochenta del siglo pasado se produjeron abundantes investigaciones y reflexiones sobre el tema, algunas de las cuales se convirtieron en trabajos clásicos (por ejemplo, Hart, 1981; Freudenthal, 1983; Kieren, 1988; Kerslake, 1986). 
Adicionalmente, el tema es reconocido por los profesores de este nivel educativo como uno de los más difíciles de enseñar. Es común que, ante cualquier diálogo con ellos el tema que surge de inmediato es precisamente el de las fracciones. ${ }^{2}$

Los resultados de los exámenes aplicados a los niños que finalizan la educación primaria por el Instituto Nacional para la Evaluación de la Educación en México (Bases de datos Excale 2005, 2007, 2009, 2013, Planea, 2015) son coincidentes con la mirada docente; al finalizar este nivel educativo, los niños tienen dificultades de todo tipo para aprender lo relacionado con este ámbito numérico. Veamos algunos datos.

Según el Examen Nacional de Logro Académico (Excale) 2013: Identificar una representación numérica de un número fraccionario dado en forma gráfica, obtiene únicamente $50 \%$ de aciertos y Resolver un problema aditivo con números fraccionarios de distinto denominador sólo alcanza 22\% (Excale 2013). Las dificultades se observan igualmente en los resultados del examen PLANEA 2015,3 conforme al cual $60.5 \%$ de los niños de sexto grado se ubican en el nivel más bajo (insuficiente) de aprovechamiento en matemáticas, lo que significa que sólo escriben, y comparan números naturales (INEE, 2015). Es únicamente $6.8 \%$ de los estudiantes el que "compara números decimales; resuelve problemas aditivos con números decimales y fraccionarios; resuelve problemas que implican dividir o multiplicar fracciones por números naturales; ubica una fracción en la recta numérica y usa las fracciones para expresar el resultado de un reparto" (INEE, 2015).

Si bien algunos investigadores han elaborado y experimentado propuestas de enseñanza tendientes a promover un acercamiento comprehensivo de las fracciones -y algunas de ellas han sido incorporadas al currículo oficial - la situación se mantiene en un nivel de logro escolar muy bajo y aparentemente sin perspectivas de mejora. Eso es lo que parecen mostrar los Excale y más recientemente el examen Ilamado PLANEA (2015).

¿Por qué estos resultados tan poco satisfactorios en el aprendizaje de las fracciones?, ¿Hasta dónde los planteamientos curriculares contribuirán a generarlos?, ¿Será la enseñanza que tiene lugar en las aulas la que actúa en desmedro del aprendizaje? Hoy sabemos que son muchos los factores que inciden en el aprendizaje, pero en este escrito destaco la relevancia del currículo -es decir, la forma en que el tema se propone en programas y libros de texto-como

2 Esto lo he constatado en el trabajo con profesores en servicio a lo largo de muchos años.

3 PLANEA: Plan Nacional para la Evaluación de los Aprendizajes 
factor que favorece o dificulta un aprendizaje adecuado de los números que nos ocupan. En tal sentido, considero que el currículo y los materiales que lo acompañan tienen incidencia en el hacer de los profesores desde el momento que facilitan o dificultan la realización de ciertas actividades al ofrecer, o no, sugerencias para la enseñanza y el soporte material para llevarlas a cabo.

Me centraré en tres propuestas educativas -y sus correspondientes libros de texto- que tuvieron gran relevancia en México, tanto por el tiempo que estuvieron vigentes, como por las ideas que introdujeron o legitimaron: el currículo de 1960, basado en una didáctica intuitiva, el de 1972, conocido como de las matemáticas modernas y el de 1993, con orientación constructivista. ${ }^{4}$ En el análisis pongo de relieve los siguientes elementos: a) el contexto pedagógico en que tuvieron lugar, b) los sub-constructos de las fracciones que fueron incluidos y c) los acercamientos propuestos para vincular el conocimiento informal que dota de significado a las fracciones con el conocimiento técnico simbólico que "formaliza" el conocimiento y que se comunica en la escuela.

Para realizar el análisis me valdré del marco desarrollado por Thomas Kieren (1988), el cual ampliaré con elementos aportados en trabajos más recientes. Aunque conviene destacar que la actualidad de la propuesta de Kieren se constata porque dichos trabajos siguen teniendo como referencia las ideas de este autor. Conviene mencionar que la amplitud del tema no permitió analizar con detalle todos los aspectos de los acercamientos planteados, lo que se presenta es sólo una visión general que posteriormente podrá profundizarse en escritos más focalizados.

\section{MARCO CONCEPTUAL}

\section{LOS SUB-CONSTRUCTOS DEL CONCEPTO FRACCIÓN}

La idea principal tomada de Kieren (1988) es su planteamiento sobre los sub-constructos que, en conjunto, constituyen el "gran concepto" que es el número racional. Este investigador expuso, hace ya 30 años, la idea de que un conocimiento completamente desarrollado del número racional tendría la estructura componencial que se muestra en la figura 1 :

4 No incluyo el currículo introducido en 2011 porque, con algunas modificaciones no siempre tendientes a la mejora del previamente vigente, las ideas son muy similares a las promovidas en 1993. 
Figura 1. Sub-constructos del número racional según Kieren

\begin{tabular}{|l|l|l|l|}
\hline Medida & Cociente & Razón & Operador multiplicativo \\
\hline
\end{tabular}

Kieren (1988) afirma que la construcción de un conocimiento duradero sobre los números racionales, hace necesario que una persona participe en actividades mentales o físicas tales que pueda asociar las expresiones "a/b" con objetos/ acciones en cualquiera de esos cuatro sistemas connotativos (p. 166): medida, cociente, razón y operador multiplicativo. No se incluye en esta estructura la fracción como una relación entre la parte y el todo. Esta relación es considerada por Kieren como "base para instaurar los diferentes sub-constructos" (Real, Gómez y Figueras 2013, p. 22).

Kieren declara que: si bien sus ideas son teóricas en el sentido de que no habían sido experimentadas, para sostenerlas se apoyó en otros autores, como D. Kerslake (1986), quien señaló enfáticamente las limitaciones en el pensamiento de los niños sobre las fracciones debidas a la adopción casi exclusiva del modelo parte-todo en las escuelas. Kerslake, después de un cuidadoso estudio planteó:

[...] mientras las interpretaciones de la fracción a/b como una región geométrica dividida en "b" partes de las cuales se toman "a" partes, era aceptado por todos los niños participantes en el experimento de enseñanza, otras interpretaciones posibles no estaban disponibles en los niños (1986, p. 88).

Quizás el dato más "duro" sobre este punto es que cuando se pedía a los niños considerar varios modelos para la fracción $3 / 40$ o 3/5, incluyendo la relación parte-grupo y el modelo de razón, éstos no sólo fueron rechazados como posibles ejemplos de las fracciones por la mayoría de los niños, sino que la razón del rechazo era, invariablemente, que "no había una figura completa para dividir" (Kerslake, 1986, p. 88).

Kieren (1988), en acuerdo con las ideas de Kerslake dice: "[...] el modelo parte-todo puede ayudar a producir fácilmente el lenguaje fraccionario, sin embargo, el lenguaje escolar sobre las fracciones en los libros de texto y en los maestros [que adoptan este modelo] tiende a orientar a los alumnos a una imagen y conocimiento estático de las fracciones" (p. 177) 
Ahora bien, ¿por qué utilizar el modelo de Kieren como marco para el análisis? Son varias las razones para hacerlo: porque-además de ser el marco que orienta en cuanto a las fracciones la última reforma curricular que analizo en este artículo (SEP, 1993) y estar vigente entre investigadores y educadores de distintas regiones (por ejemplo, Llinares, 2003, Fandiño, 2009, Charalambous y Pitta-Pantazzi, 2005, Charalambous, 2007, Real, Gómez y Figueras, 2013, Ivars, Boufort y Llinares, 2016, Zazkis y Mamolo, 2018)- su adopción permitió comparar los tres períodos curriculares objeto de análisis. Pero la principal razón para utilizarlo, es que el modelo de los sub-constructos, gracias a su completitud, marca un horizonte desde el cual mirar comprehensivamente el aprendizaje y la enseñanza de las fracciones. De esto es muestra la utilización y citación frecuentes de este modelo aun en las investigaciones más actuales 5 .

\section{EL TRÁNSITO DEL CONOCIMIENTO ETNOMATEMÁTICO AL TÉCNICO-SIMBÓLICO}

La idea de los sub-constructos como elementos constituyentes del "mega-constructo" número racional es sin duda la aportación de Kieren más reconocida. Pero otro aporte de este autor, también fundamental por su contribución a nuestro entendimiento de las fracciones como objeto de enseñanza, es el que refiere a la relación entre el conocimiento informal, que él llama etnomatemático, y el conocimiento técnico-simbólico (Kieren, 1988), postulada como necesaria para una comprensión cabal de los números racionales. La razón que justifica la postura es que: "[...] los constructos menos formales proveen una base de significado para el conocimiento más formal y una base crítica para validar 'verdades' simbólicas o principios normativos" (p. 166).

¿Cómo se transita entre uno y otro nivel? El postulado (Kieren,1988) es que, en la construcción del número racional, las imágenes -en el sentido físico, pictórico, o mental- tienen un papel muy relevante. La idea de mitad, por ejemplo, está asociada a imágenes de cortar, de simetría e incluso de calcular numéricamente la mitad. Recurriendo a D'Ambrossio, Kieren hace notar que este conocimiento no es escolar, sino que se construye porque se vive en un contexto particular, por lo que es un conocimiento etnomatemático (CE).

\footnotetext{
5 Hay quienes, siguiendo a Davydov y Tsvetkovich (1991), se han apartado de este modelo para enfatizar la idea de medida, como Saldaña y Thompson, o Cortina y sus colegas, pero aún no se conoce el impacto que esta propuesta ha tenido o puede tener en el aprendizaje de las fracciones.
} 
Un segundo nivel de conocimiento es el intuitivo $(\mathrm{Cl})$ que comúnmente es enseñado e involucra deliberadamente la conjunción de imágenes, mecanismos constructivos (en el sentido de Kieren) y un uso informal del lenguaje (Kieren, 1988). Se trata de un conocimiento que no es técnico o lógicamente formalizado pero que constituye un eslabón entre el etnomatemático y el técnico-simbólico.

El conocimiento técnico simbólico (CTS) se construye mediante el uso de lenguaje [matemático] estándar, notaciones y algoritmos; es un conocimiento enseñado. Para que este conocimiento sea estable y útil, debe ser comprobable contra alguna forma de "realidad" o representar alguna secuencia lógica local que pueda ser evaluada en términos de axiomas para los números racionales (Kieren, 1988, p. 170).

Desde esta perspectiva, entonces, la construcción del conocimiento sobre las fracciones ha de considerar el conocimiento etnomatemático como primer referente y transitar por el conocimiento intuitivo, para llegar al más "formal" propio del nivel técnico-simbólico.

Siguiendo el pensamiento de Kieren, considero que el tránsito de un tipo de conocimiento a otro se acompaña de diferentes tipos de lenguaje. De hecho, como señalaría el autor, la experiencia previa y el lenguaje son fundamentales en la construcción y representación mental de los conocimientos matemáticos, incluidos los relacionados con las fracciones (Kieren, 1999).

\section{METODOLOGÍA}

\section{PREGUNTAS DE INVESTIGACIÓN}

El interés por revisar las propuestas de enseñanza de las fracciones, motivo de este escrito, se expresa en las preguntas que anoto a continuación.

En los currículos y libros de texto gratuitos ${ }^{6}$ utilizados en la educación primaria mexicana, entre 1960 y 2011:

- ¿Qué significados o sub-constructos de las fracciones se incorporaron?

- ¿Qué relaciones entre el conocimiento etnomatemático (informal) y el técnico-simbólico se establecieron?

6 Desde 1960, la Secretaría de Educación Pública distribuye gratuitamente libros de texto a todos los niños que cursan la educación primaria. Las guías didácticas se entregan a los maestros de este nivel educativo. 
- ¿Qué lenguaje se utiliza en los distintos materiales y qué papel juega dicho lenguaje?

- ¿En qué contexto pedagógico se desarrollaron e implementaron dichas propuestas?

- ¿Qué puede ofrecernos la revisión de estas propuestas para mejorar la enseñanza?

\section{ESTRATEGIA DE INDAGACIÓN}

Como mencioné, se analizan los programas y libros de texto distribuidos por la Secretaría de Educación Pública que fueron utilizados en la educación primaria mexicana el último medio siglo, a saber: a) la propuesta curricular de 1960, que definiré como didáctico-intuitiva; b) la propuesta introducida en 1972, o de la matemática moderna; c) la propuesta instrumentada en 1993 y que llamaré constructivista.

La revisión de los materiales se realizó mediante acercamientos sucesivos consistentes en:

1. Búsqueda y recopilación de planes de estudio, programas, guías para docentes y libros de texto gratuitos de matemáticas distribuidos por la Secretaría de Educación Pública en el período ya señalado.

2. Identificación de contenidos, aprendizajes esperados y secuencias de enseñanza vinculados a las fracciones, propuestos en los distintos materiales.

3. Análisis de los planteamientos curriculares y las lecciones dedicadas a las fracciones con base en el marco conceptual elegido.

\section{RESULTADOS}

\section{ETAPA DIDÁCTICO-INTUITIVA DE LA ENSEÑANZA DE LAS FRACCIONES}

\section{Centración en el modelo parte-todo y prevalencia del nivel técnico-simbólico}

En ese período, las fracciones se denominan "quebrados", aunque el término fracción se utiliza eventualmente en los últimos grados. Tal denominación refleja la concepción de fracción propia de este currículo pues, efectivamente, ésta es 
vista como parte de algo que se ha fracturado. Razones y proporciones y porcentajes se estudian en los dos últimos grados de la primaria, pero su tratamiento se hace estableciendo una débil relación explícita con la fracción y el modelo "parte todo" (SEP, 1961 y 1962).

A lo largo de la primaria, es permanente y casi exclusiva la referencia a dicho modelo. Los "quebrados" se introducen en vinculación con el conocimiento etnomatemático mediante imágenes que ilustran partición de frutas con forma más o menos regular: naranjas, melones o manzanas. Esta idea permanece a lo largo de la primaria, pero las frutas son sustituidas paulatinamente por figuras geométricas y, al final, sólo quedan los símbolos y el lenguaje técnico-simbólico pues, según las recomendaciones de la época "la enseñanza de la aritmética debe ir de lo concreto a lo abstracto" (SEP, 1968).

Hay efectivamente un intento por vincular el conocimiento técnico-simbólico (CTS) con el que los niños han construido en su experiencia cotidiana (CE), transitando por el nivel intuitivo $(\mathrm{Cl})$-que implica la vinculación con imágenes familiares y un uso informal del lenguaje. Esto se ve, por ejemplo, en la lección que abre la enseñanza del tema en primer grado (figura 2). Ahí se muestran frutas partidas en mitades y cuartas partes que luego "se convierten" en figuras geométricas divididas en partes iguales acompañadas de lenguaje natural.

Figura 2. Lección con que se iniciaba el trabajo con las fracciones en la escuela primaria en los años 1960 (SEP, 1960a, p. 101).

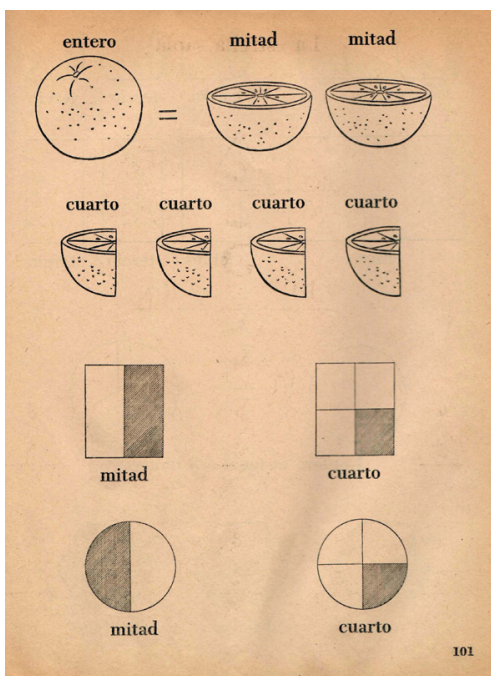


En concordancia con la idea principal de la propuesta, las representaciones utilizadas en los cuatro primeros grados aluden al modelo parte-todo. Se reitera el uso de las dos representaciones ya mencionadas: dibujos de frutas partidas y formas geométricas - principalmente círculos, cuadrados y rectángulos- cuyo parecido figural con la fruta seguramente tenía un valor didáctico importante en el tránsito de lo concreto a lo abstracto. Ya desde el tercer grado predominará el nivel TS. A partir de este grado, una exposición de imágenes consideradas cotidianas (como frutas o listones) incluidas como apertura de las primeras lecciones parece considerarse suficiente para vincular los niveles E y TS y privilegiar este último en el resto del libro. Lo anterior puede observarse en la figura 3. En la lección ahí presentada, después de una narrativa que contextualiza el tema (no incluida en la figura), siguen páginas donde se eliminan gradualmente las imágenes para transitar al nivel TS y mantenerse en él. Efectivamente, la vinculación CE-Cl-CTS pronto se deja a un lado y se trabaja con afirmaciones "formales", notaciones y algoritmos:

Figura 3. Páginas de una lección de tercer año (SEP, 1960c, pp. 54-55) en las que se observa el tránsito al nivel técnico simbólico. Las siguientes páginas tratan, de manera similar, otras fracciones.

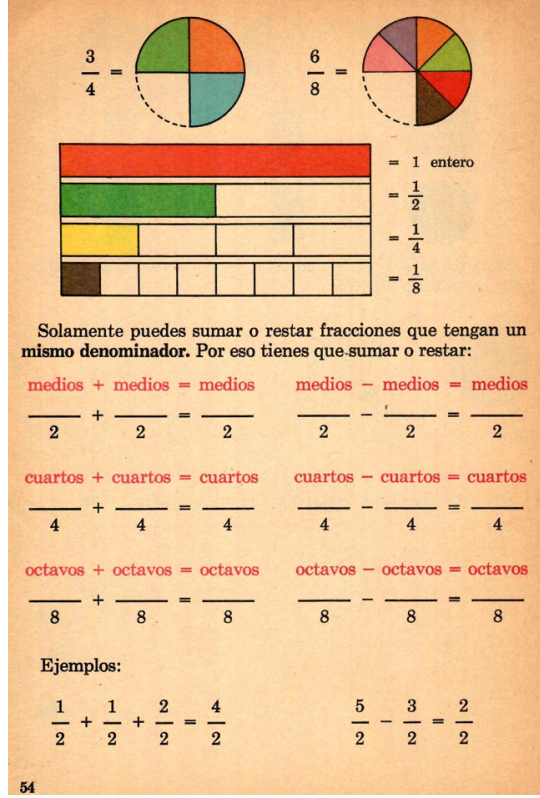

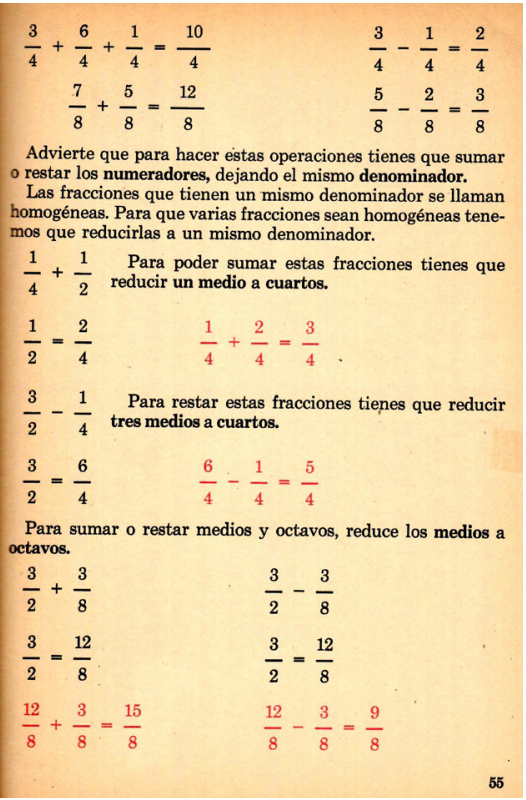


La secuencia concluye con la siguiente formalización:

A

"Solamente puedes sumar o restar fracciones que tengan un mismo denominador.

Por eso tienes que sumar o restar "medios + medios" + medios", o "Cuartos + cuartos

+ cuartos", etcétera (SEP, 1960c, p. 54).

\section{El lenguaje sobre las fracciones}

A pesar de que, como se ha afirmado, este currículo privilegia el nivel TS, la definición de fracción merece poca atención, de tal suerte que el primer intento de formalización de la noción se ve en una lección de quinto grado:

B

Las fracciones comunes, llamadas también quebrados, se escriben así:

$1 / 2$, que se lee un medio y significa la mitad de algo.

$1 / 3$, que se lee un tercio, y significa la tercera parte de algo.

$4 / 5$, que se lee cuatro quintos, y significa las cuatro quintas partes de algo.

(SEP. 1961a, p. 53).

Tal formalización evoca la relación parte-todo y se complementa después con otra incluida en el libro de sexto grado (SEP,1970, p. 43), donde la referencia es a la idea de medida:

C

Para expresar el valor de cantidades que no contienen un número exacto de veces la unidad elegida, o de cantidades menores que la unidad, se han creado las fracciones

comunes.

Aunque a esta formalización no le precede ninguna narración o imagen tendientes a darle significado, pues la fracción en contexto de medición no fue trabajada. 
Llama la atención que, aunque, como he destacado, la orientación de este currículo privilegiaba el nivel TS, la definición de fracción no es central; en vez de trabajarla con más detenimiento, la atención se dedica a otras definiciones respecto de procedimientos o aspectos de estos números, por ejemplo: a) los nombres de los términos de la fracción; b) fracciones propias e impropias y c) procedimientos para ordenar fracciones y para operar con ellas.

Al final de la primaria el abandono del nivel intuitivo (NI) es más marcado y se realiza un trabajo casi exclusivo en el nivel TS. Así, en el libro de sexto año, de 22 páginas dedicadas a las fracciones, sólo 6 contienen imágenes, todas similares a las utilizadas en los grados precedentes (figura 4a). Con tal enfoque, los procedimientos más complejos ya no se ilustran, sólo se describen y ejemplifican (nivel TS) (figura 4b). El libro de sexto, por lo mismo, se asemeja más a un compendio del contenido de toda la primaria que a un libro de texto de aritmética y geometría elemental.

Figura 4a. Página del libro de sexto año. Aritmética y Geometría donde se incluyen imágenes. (SEP 1970, p. 44).

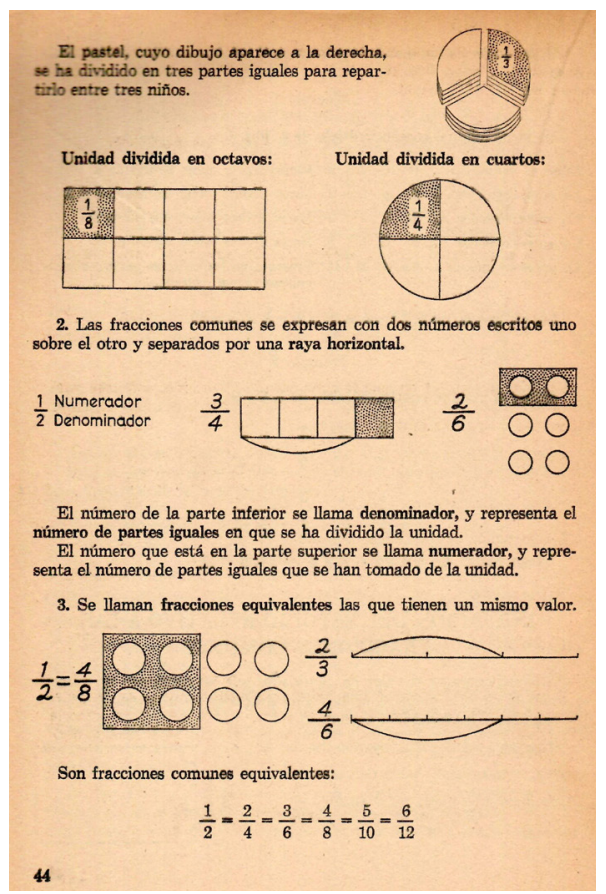

Figura 4b. Página típica del libro de sexto año, Aritmética y Geometría (SEP, 1970, p. 55) 


\section{Introducción de la noción de razón}

En el quinto grado se introduce la noción de razón, enfatizando la idea de comparación por cociente. No se hace referencia explícita a que éste es otro significado de la fracción, sólo se usa la notación fraccionaria (SEP, 1961, p. 85). El tema se inicia mediante un discurso descriptivo (nivel TS) que indica lo que ha de mirarse en la situación (figura 5):

Figura 5. Lección de sexto grado en la que inicia el trabajo con las razones y proporciones (SEP, 1961, p.85).

\section{RAZONES Y PROPORCIONES}

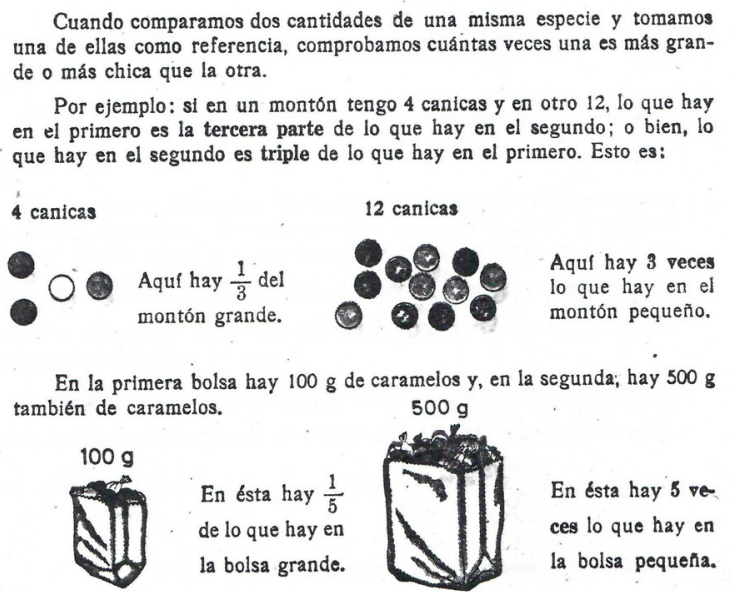

La formalización y definición presentadas al final de la lección son las siguientes:

Figura 6. Formalización de la noción de razón en el libro de quinto año. Aritmética y Geometría. Estudio de la Naturaleza (SEP. 1961, 86).

D

Razón es el resultado de comparar por cociente dos cantidades de una misma especie. Así, la razón del número de canicas del primer montón respecto del segundo es 1/3 (Primer ejemplo).

La razón de $100 \mathrm{~g}$ de caramelos a $500 \mathrm{~g}$ de caramelos es 1/5 (segundo ejemplo) 
En concordancia con el enfoque asumido, el resto del tema se conduce en el nivel TS mediante ejercicios de cálculo, al igual que la noción de proporción, que inicia con la siguiente definición: "Cuando hay dos razones iguales se forma una proporción" (SEP, 1961, 89).

\section{CONCLUSIONES SOBRE LAS FRACCIONES EN EL CURRÍCULO DE 1960}

En este período el sustento casi exclusivo de la noción de fracción es el modelo parte-todo. De primero a cuarto grado, las expresiones de la forma a/b tienen como referente único la idea de partir un objeto en partes iguales y tomar cierto número de ellas. La equivalencia entre fracciones también se asocia a dicho modelo y se ilustra sobre objetos simples del entorno y figuras geométricas en general regulares. Por supuesto, el objetivo era alcanzar el manejo simbólico y culminar con la idea de que: al multiplicar el numerador y el denominador de una fracción por el mismo número se obtienen fracciones equivalentes.

En los primeros grados se utilizaba lenguaje natural para referirse a los medios y los cuartos, pero en general, el uso del lenguaje estaba fuertemente vinculado al nivel TS. En prácticamente todas las lecciones se incluía alguna formalización, definición o procedimiento expresado mediante este lenguaje, y en los últimos grados el trabajo se realiza principalmente en dicho nivel. Es el caso de las nociones de razón y proporción, que fueron trabajadas en esos grados, sin haberse producido suficientes intuiciones para apoyar su comprensión. En general, el lenguaje que acompañaba a las situaciones era descriptivo o enunciativo y en muchos casos las definiciones se incorporaban sin haberse ofrecido un respaldo experiencial (a través de las imágenes) que permitiera a los alumnos verificar su validez.

Para ser justos en la valoración de esta propuesta, conviene recordar que, en 1960, la didáctica de las matemáticas como disciplina científica apenas nacía. No se contaba aún con resultados de investigaciones que permitiesen orientar con bases científicas la enseñanza de las matemáticas. Producto de este contexto, la idea de fracción que se comunicaba hoy parece en extremo estática y limitada. Pero es que se trataba de un período donde en la base estaba una teoría emparentada con el sensual-empirismo. Conforme a esta teoría, se creía que el aprendizaje se daba a través de los sentidos y el alumno era considerado un receptor que asimilaba los conocimientos en la forma en que se le presentaban; de ahí la importancia de las imágenes. 
Hoy este acercamiento resulta del todo cuestionable puesto que, además de que el modelo parte-todo determinaba el sentido y el límite de las fracciones, se consideraba que una presentación inicial (ostensiva) del conocimiento etnomatemático bastaría para que el conocimiento técnico-simbólico se impregnara de significado. No podía ser de otro modo. En ese entonces, la ostensión constituía el horizonte de la acción didáctica en Aritmética y geometría: el conocimiento entraba por los sentidos, y se generaba mediante intuiciones creadas a partir de las imágenes. Tal forma de concebir las fracciones y promover su enseñanza se vería modificada con el ingreso de la reforma de los años 70.

\section{LA MATEMÁTICA MODERNA O LA TRANSICIÓN A LA DIDÁCTICA}

\section{NUEVOS SIGNIFICADOS Y NUEVOS LENGUAJES PARA LAS FRACCIONES}

El currículo introducido en 1972, conocido en México como "La reforma de las matemáticas modernas", trajo grandes cambios en la forma de pensar las matemáticas y su enseñanza en la educación primaria. Las reflexiones de Bruner y de Dienes tendían un nuevo horizonte para la enseñanza de dicha disciplina (Avila, 2006). De ahí que un principio fundamental para enseñarla fuera el siguiente: "Que sean los mismos niños quienes vayan descubriendo las nociones" (Imaz, coord., 1977, p. 6). Porque, "...] se habrá de aprovechar el caudal de nociones intuitivas que el niño ya maneja, por sus vivencias cotidianas, construir sobre ellas tratando de refinar tales nociones por medio de situaciones concretas en las que éstas se presentan de maneras sencillas, hasta alcanzar, a través de la práctica reiterada, el concepto que interesa captar". (Gorostiza y Rivaud (coords.), 1974, p. 8).

Esta nueva perspectiva tuvo efectos sobre la forma de relacionar a los alumnos con las fracciones; las ideas sobre estos números se ensancharon, iniciándose una apertura hacia el "gran concepto de número racional":

- Se mantuvo el modelo parte-todo, pero se incorporó también la fracción como cociente (introducida como resultado de un reparto), como razón (vinculada a las escalas) e incluso como operador.

- Se ampliaron las representaciones de la fracción, incluyéndose todos discretos y la recta numérica como medios de representación 
- Se incluyeron problemas que implicaban orden y operaciones con fracciones.

- Se establecieron puentes más sólidos entre el conocimiento etnomatemático (CE) y el técnico-simbólico (CTS), mediante un tránsito más pausado por el nivel intuitivo $(\mathrm{Cl})$.

- El lenguaje se modificó: se mantuvo el descriptivo propio de los años sesenta, pero se agregaron dos nuevos formatos: el argumentativo (que expresa razones yendo más allá de las descripciones), y el interrogativo (que lleva a expresar conclusiones a partir de regularidades observadas en casos particulares).

Efectivamente, aunque el enfoque general estaba cargado hacia la disciplina matemática (Block y Álvarez; 1999), en el caso de las fracciones se observa interés por establecer mejores vínculos entre los distintos niveles de conocimiento. Veamos esto en el trayecto que sigue la fracción a lo largo de la primaria.

\section{La noción de fracción}

La noción de fracción en este currículo presenta una cierta ambivalencia: Ilamarse quebrado y a la vez llamarse fracción. Esta ambivalencia se observa a lo largo de la primaria. La noción se introduce en segundo grado apelando a las experiencias cotidianas de los niños: se presentan mitades o cuartos de pasteles, frutas, colecciones de objetos, o precios de juguetes que se fraccionan en terceras o cuartas partes.

A primera vista, este acercamiento es similar al de los años sesenta, pero no es así, pues además de una parte de un todo continuo, la fracción es también una parte de una colección de objetos y una parte de una cantidad distinta de uno (véase figura 6).

En este acercamiento introductorio se incluye también la representación de algunas fracciones en la recta numérica (figura 7). Una representación aparentemente tan alejada del pensamiento de los niños pequeños era considerada accesible porque se suponía dotada de significado a través de "los saltos de la rana", recurso didáctico utilizado profusamente con los números naturales en el primer grado. 
Figura 6. Páginas del libro de segundo grado en las que inicia el tratamiento de las fracciones (SEP, 1972a, pp. 105, 110 y 111).
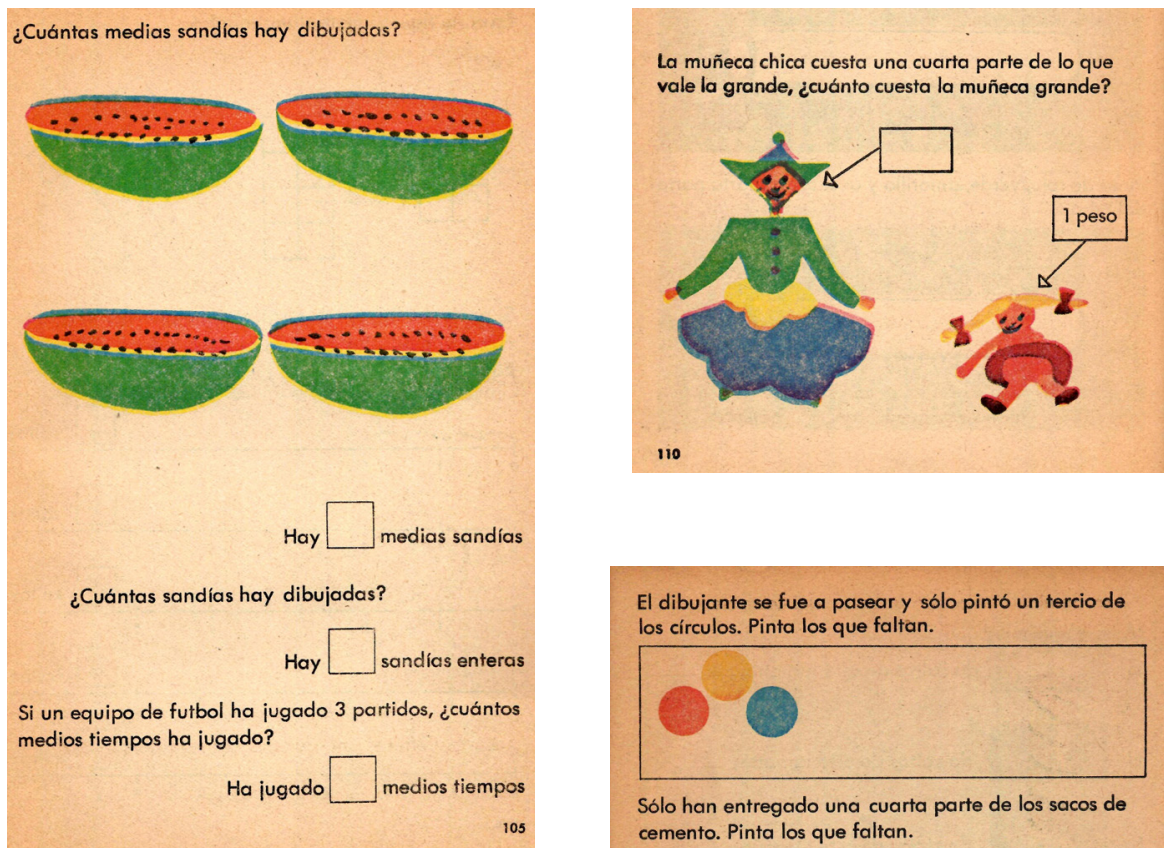

Sólo han entregado una cuarta parte de los sacos de cemento. Pinta los que faltan.

Figura 7. Introducción, en el segundo grado, de las fracciones en la recta numérica. (SEP. 19721a, p. 107).

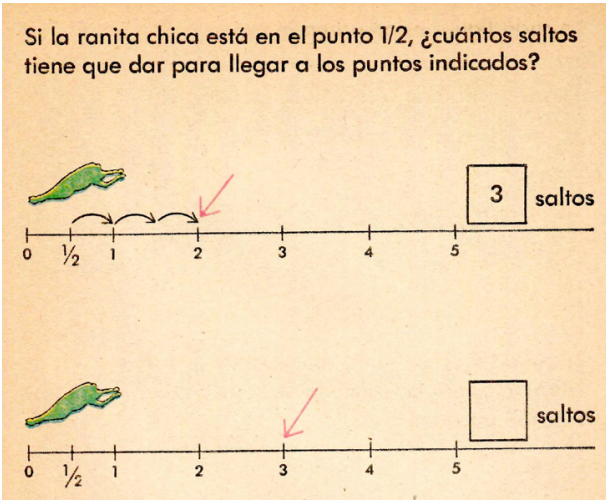


Pero la noción no se limita a lo anterior; en tercer grado se incorpora la idea de fracción como resultado de un reparto (tendiente a la idea de cociente) mediante el planteamiento de problemas del tipo siguiente:

E

"Diez niños se van a repartir dos papayas. Forman dos grupos de 5 niños cada uno y cada grupo se divide una papaya en partes iguales. A cada niño le toca de papaya". (p. 207, libro de tercer grado, subrayado mío).

La parte-todo y el cociente se alternarán a lo largo de la primaria y se complementarán con la idea de razón (asociada a las figuras a escala) y la de operador, trabajada con detenimiento en los últimos grados, mediante problemas del tipo: "Cinco octavas partes de los animales de un zoológico son mamíferos y 2 de cada 25 mamíferos son fieras. Si el zoológico cuenta con 3000 animales, ¿cuántas fieras puedes hallar en el zoológico?" (SEP, 1972, p. 253) ${ }^{7}$.

Este sub-constructo desembocará en la multiplicación de fracciones, que se dota de significado mediante un amplio tratamiento basado en la graficación de la idea "una parte de" sobre fracciones unitarias y no unitarias: "el resultado de multiplicar una fracción por otra es una parte de esa otra", lo que se formaliza mediante la operación mencionada (figura 8).

7 Coincido con Real, Gómez y Figueras (2013), en que la interpretación de la fracción puede modificarse en una situación, por ejemplo, en una situación de escalas, inicialmente se trata de una razón, y se transita a la de operador cuando se resuelve el problema. 
Figura 8. Página de libro de quinto grado dedicada a ilustrar la multiplicación de fracciones (SEP, 1972c, p. 177).

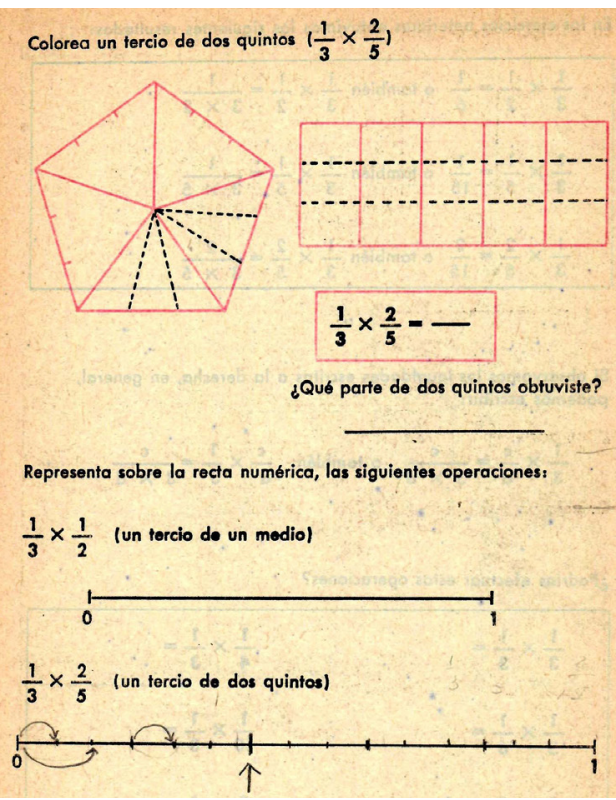

Posteriormente, la operación se utiliza para resolver problemas del tipo siguiente:

$\mathrm{F}$

4/7 partes del espacio de un librero está ocupada por libros, y de éstos, las enciclopedias ocupan la tercera parte, ¿Qué parte del librero ocupan las enciclopedias?

(SEP, 1972c, p. 256)

Es importante señalar que la idea de fracción como cociente (resultado de un reparto) se desarrolla sin apoyo de representaciones gráficas. Son situaciones planteadas verbalmente las que vinculan al sub-constructo con el CE de los estudiantes, tal como se ve en el problema inserto en el recuadro E. Esto se debe probablemente a que la actividad de repartir está más vinculada a la acción 
efectiva que la de sombrear figuras (Kerslake, 1986, p. 90), y al ser más dinámica, es más difícil de representar.

Es así que, aunque las situaciones no corresponden sólo al modelo dominante, en general, las representaciones gráficas sí. Es hasta que se incorpora la equivalencia - a partir de la idea de "reparto" (SEP, 1975, pp. 109, y 110)- cuando se incluyen representaciones gráficas de algunos repartos (figura 9). Con este tipo de imágenes se busca generar un $\mathrm{Cl}$ que apoye la comprensión de la noción.

Figura 9. Página del libro de cuarto grado en la que se incorpora la idea de equivalencia con base en repartos equivalentes. La página siguiente contiene ejemplos similares.

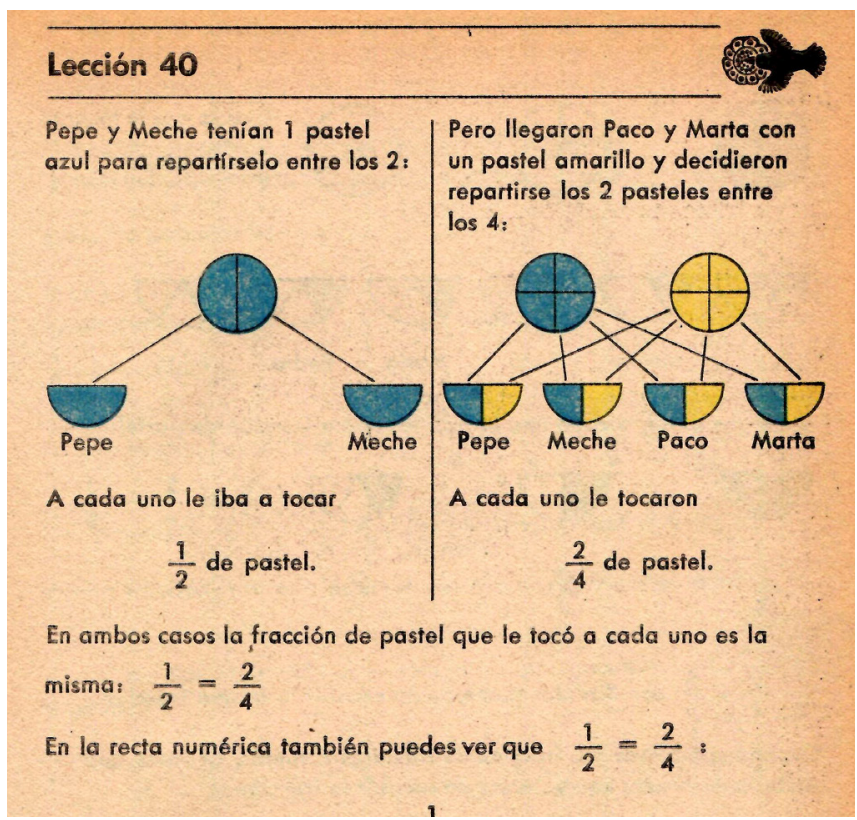

\section{El lenguaje}

En los primeros grados predomina el lenguaje natural; la incorporación decidida del lenguaje TS comienza hacia la mitad de la primaria, con referencia al modelo parte-todo (figura 10). 
Figura 10. Página del libro de tercer grado, donde se observa el tránsito al nivel técnico-simbólico sustentado básicamente en el modelo parte-todo (SEP, 1972b, 203).

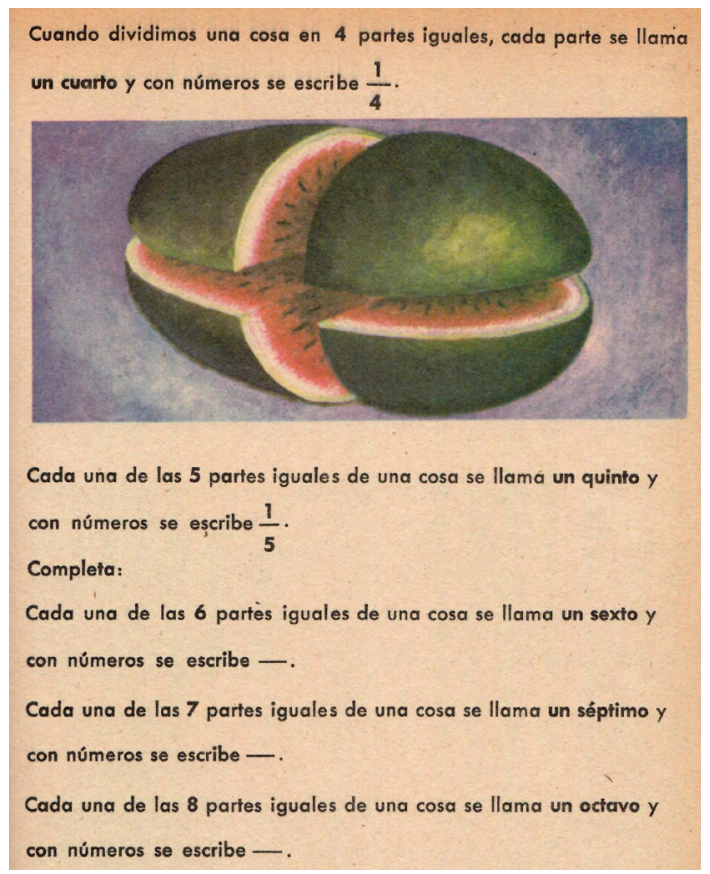

La representación gráfica del modelo se alterna con "todos intangibles", como la hora o los minutos, concluyendo, después de varios ejemplos, con la siguiente formulación:

G

"Los números como $1 / 2,1 / 3,1 / 4$ se llaman quebrados o fracciones"

(Libro de tercer grado, p. 205).

Frases idénticas se reiteran en tercero y cuarto grados, siempre destacadas en recuadros y precedidas de ejemplos y ejercicios sobre representaciones gráficas del modelo. Pero en este período, como se verá en seguida, el lenguaje y su uso se complejizaron. 


\section{El lugar del lenguaje "formal"}

No obstante la recurrencia al modelo parte-todo y el uso de frases enunciativas, una diferencia con el currículo de los años sesenta es el lugar del lenguaje: a las formulaciones y definiciones las preceden una cantidad importante de representaciones gráficas. Esto es, hay un tránsito más pausado por el nivel intuitivo, el cual tiene por objetivo dotar de significado a las "formalizaciones matemáticas". En consecuencia, el lenguaje matemático "formal" generalmente se ubica al final de las lecciones.

En otros casos, el lenguaje se torna argumentativo (trata de exponer las razones que subyacen a las formulaciones), como en la multiplicación que, a través de acciones sobre imágenes, intenta mostrar las "razones" del significado de la operación (figura 8).

En algunas ocasiones, se introduce un lenguaje que acompaña más abiertamente al razonamiento inductivo, promovido mediante la observación guiada de ciertas regularidades en los casos presentados. De este modo -conforme a la idea de que los niños descubran los conceptos- el procedimiento general, el concepto o la definición que interesa elaborar se formulan con base en la regularidad observada en los ejemplos y los ejercicios resueltos.

Un intento por promover el razonamiento inductivo en el caso de las fracciones lo encontramos en el libro de cuarto grado donde, después de una actividad sobre varias "rectas numéricas", en la que se constata que el punto o los puntos correspondientes a diversas fracciones es el mismo (figura 11), la secuencia se cierra formalizando la idea de que a un mismo número (mismo punto en la recta) corresponden distintas expresiones fraccionarias equivalentes (figura 12). 
Figura 11. Rectas numéricas donde se muestra la equivalencia de fracciones respecto de los puntos correspondientes a 1, 2 y 3 (SEP, 1975, p. 76)

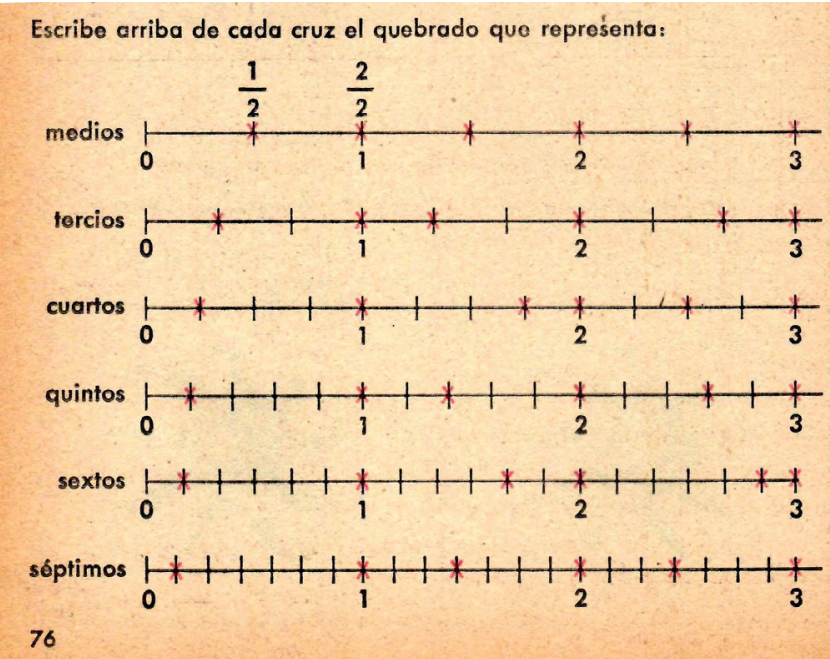

Figura 12. Lección en la que, habiendo observado puntos sobre la recta correspondientes a fracciones equivalentes (figura 11), se concluye sobre la equivalencia de fracciones y se emplea por primera vez el término equivalente. Libro del alumno. Matemáticas. Cuarto grado. (SEP, 1975: 77).

Mira las rectas numéricas anteriores para escribir en medios, tercios, hasta séptimos:

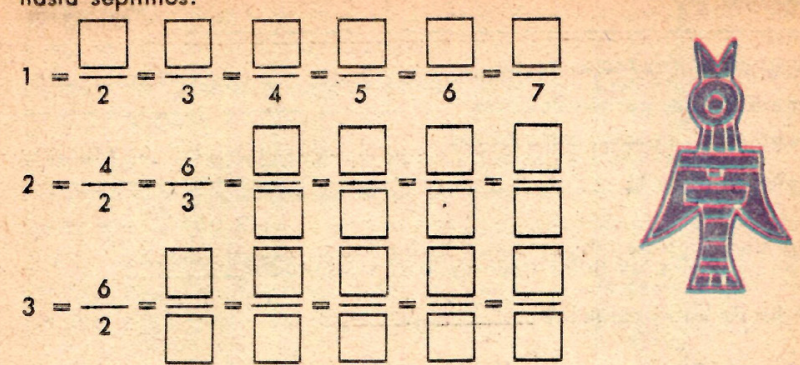

Observa que has escrito cada uno de los números 1,2 y 3 de varias maneras distinlas, que llamaremos equivalentes. 
El proceso didáctico seguido en este caso consiste en: a) resolver ejercicios donde se muestra que es posible expresar de distintas maneras una fracción (un mismo punto en la recta), b) hacer observar lo anterior, c) observar que un número puede expresarse de diferentes maneras, y d) dar nombre a lo observado: esas distintas maneras son equivalentes.

Después de un recorrido apoyado en representaciones del modelo parte-todo y la recta numérica, se concluye con una definición de equivalencia sustentada en los productos cruzados, situación que refleja el interés por formalizar el lenguaje matemático (Nivel TS) (figura 13).

Figura 13. Matemáticas. Quinto grado. (SEP, 1972c, p. 41)

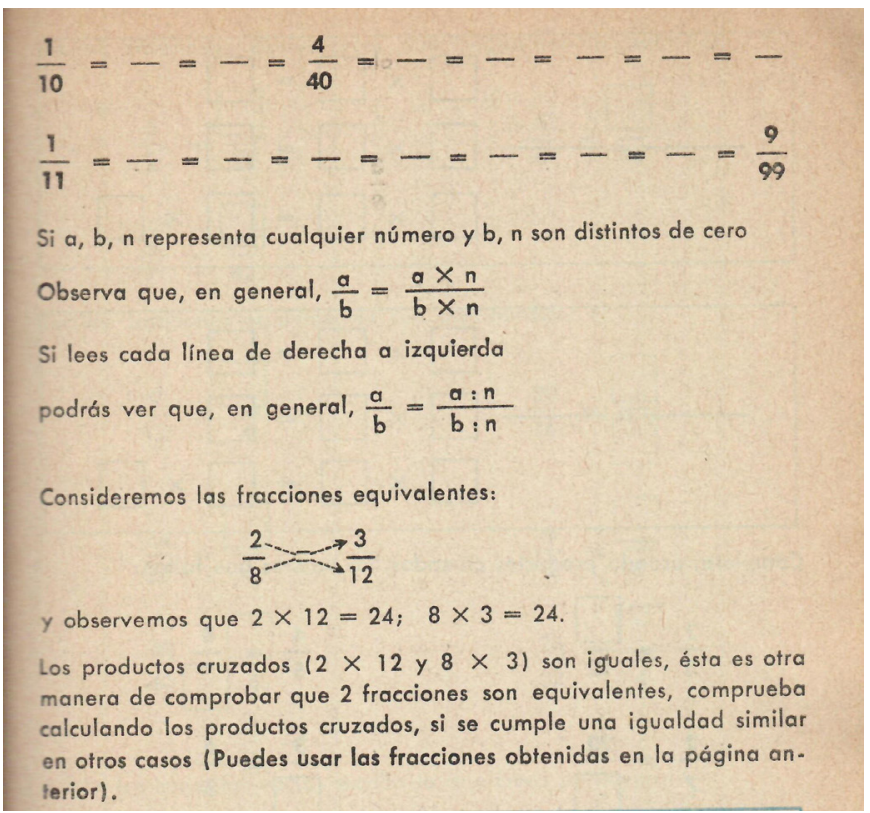

Es decir que, en algunas lecciones se buscaba la obtención de formalizaciones como corolario del proceso de descubrimiento (o de inducción). Los libros de texto eran un importante apoyo para poner en práctica tal enfoque. Aunque plasmarlo en el tratamiento de las fracciones no fue tan sencillo como en otros temas, por lo que su incorporación no fue muy frecuente. 


\section{Conclusiones sobre el currículo de 1972}

Antes mencioné, que esta propuesta implicó una primera apertura a la idea de número racional como "gran concepto" constituido por los sub-constructos medida, cociente, razón y operador multiplicativo.

Es cierto que aún se utiliza la palabra "quebrado" y que el modelo parte-todo es referente gráfico fundamental para la construcción del concepto de fracción, pero a las frutas o las figuras geométricas regulares se agregaron las irregulares, las colecciones de objetos, o los "todos" diferentes de uno expresados por ejemplo en precios, número de participantes en equipos deportivos, o de alumnos de un grupo escolar. Ya en los últimos grados se incluye la noción de operador mediante conjuntos de los que se ha de calcular una fracción.

Por otra parte, la modificación en el sustento psicológico (el aprendizaje por descubrimiento) llevó a intentos meritorios de abandonar la ostensión y el lenguaje descriptivo que le es consustancial.

A pesar de las dificultades para plasmar en todas las lecciones el enfoque previsto, el reconocimiento de que el alumno llega a la escuela con un conocimiento, y que partir de ese conocimiento es el camino pertinente para construir el conocimiento escolar, constituyó indudablemente un avance en las formas de pensar el aprendizaje y la enseñanza de las matemáticas y de las fracciones. Pero llegó el tiempo en que la propuesta sería cuestionada y sería sustituida por otra con orientación constructivista. Esto ocurrió al comenzar los años noventa.

\section{EL CURRÍCULO DE BASE CIENTÍFICA: ACENTO EN LA CONSTRUCCIÓN DEL CONOCIMIENTO Y UNA DÉBIL INSTITUCIONALIZACIÓN}

El currículo de 1993 se concibió en un contexto internacional generado por la irrupción del constructivismo en la educación básica y por un avance importante en la investigación en didáctica de las matemáticas (véase, por ejemplo, Block y Waldegg, coords.1995), contexto en el que además se vivía un fuerte desencanto por los resultados de "las matemáticas modernas" (SEP, 1993; Block y Álvarez, 1999; Avila, 2006). Resultado de lo anterior, fueron los cambios relevantes en el enfoque pedagógico para promover el aprendizaje de las matemáticas: se buscó la participación activa de los alumnos en la construcción de los conocimientos, y se incorporó la resolución de problemas como instrumento privilegiado para hacerlo (SEP, 1993). Dicha perspectiva se dejó sentir en el tratamiento didáctico de las fracciones. 


\section{Un amplio significado para la noción de fracción}

Siendo éste un currículo que contaba para su fundamentación con un amplio acervo de investigaciones sobre el aprendizaje de las fracciones, se incluyeron sistemáticamente sus diversos significados: parte-todo, cociente, medida, razón y operador (SEP, 2001, 2002a, 2002b, 2002c). Estos significados se trabajan a partir de situaciones problemáticas consideradas significativas para los alumnos: partición de cartulinas, hojas y tiras de papel para construir adornos o juguetes; repartos de pasteles, pizzas y galletas (modelados en papel); así como medición de objetos del entorno, entre otras. Las tiras de papel también fueron utilizadas para trabajar las fracciones en contexto de medición, y en los últimos grados se abordó detenidamente la idea de razón vinculada a mezclas, reglas de cambio y escalas.

El acercamiento didáctico en esta propuesta es muy distinto de los anteriores; las frutas y las figuras geométricas desaparecieron como recursos para introducir las fracciones. Las lecciones sobre el tema (que comienzan en tercer grado) incluyen situaciones problemáticas a partir de las cuales -aprovechando los conocimientos previos de los niños- se van construyendo las nociones. El acercamiento inicia con las fracciones un medio y un cuarto, que durante un tiempo no serán nombradas formalmente ni simbolizadas. La figura 14 muestra un fragmento de una lección donde la intención es que se fraccionen hojas de papel en medios y cuartos sin utilizar necesariamente los términos.

Figura 14. Fragmento de la lección del libro de tercer grado en la que inicia el tratamiento de las fracciones en el currículo.

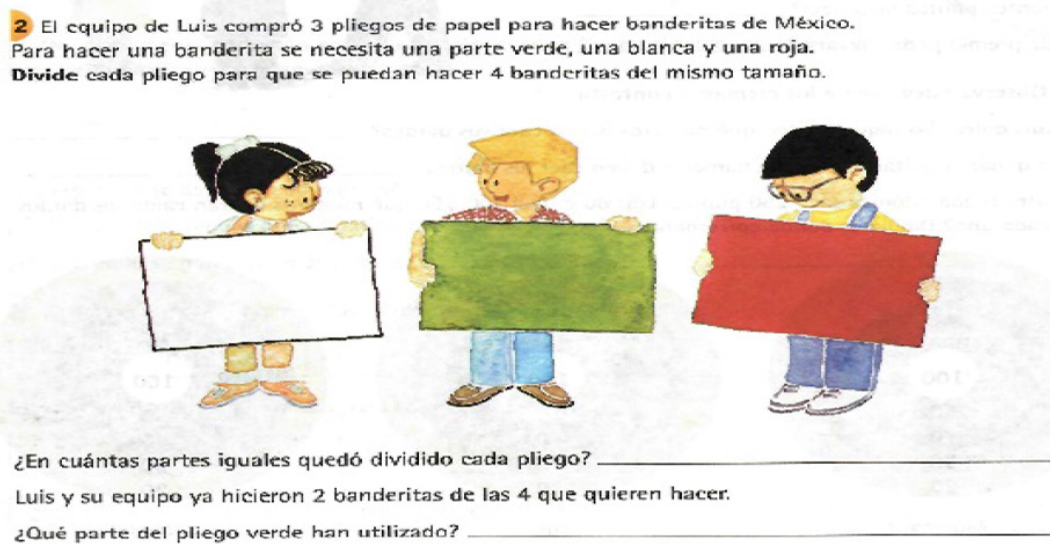


También es clara la intención de romper el esquematismo del modelo parte-todo presentando particiones no convencionales (figura 15), y vinculando las fracciones con cantidades discretas (precios) y continuas (litros o quesos) (figura 16).

Figura 15. Lección de tercer grado en la que se muestran particiones poco convencionales

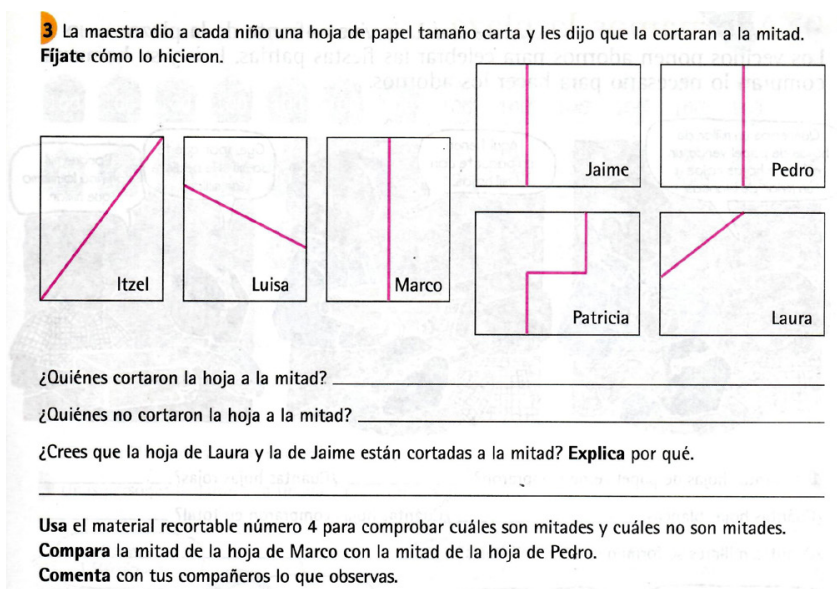

Figura 16. Fragmento de una lección donde las fracciones se vinculan a cantidades continuas y discretas (Matemáticas tercer grado. SEP, 2002a, p. 92)

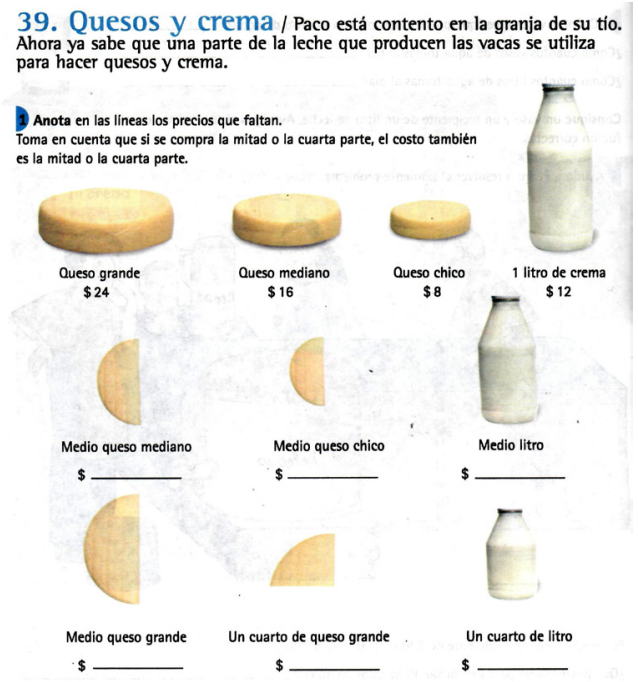


Ocasionalmente, -como al final de la lección "Quesos y crema"- se incluyen "formalizaciones" del conocimiento producto de la actividad (recuadro H):

$\mathrm{H}$

Para escribir cantidades como un medio o un cuarto, se pueden utilizar las fracciones. Un medio se escribe así: 1/2; un cuarto se escribe así: 1/4. (Matemáticas tercer grado. SEP, 2002a, p. 93)

Estas formalizaciones son muy escasas y, en general, son "formalizaciones locales", puesto que las convenciones son fijadas libremente para utilidad del grupo y el avance en el estudio de la lección. Bajo el escaso interés por las formalizaciones, la primera vez que se utiliza el lenguaje técnico simbólico es en la lección Quesos y crema. En las cinco lecciones previas todo se ha expresado en lenguaje natural.

También se incluyen situaciones donde aparecen las fracciones en contexto de medición, con referencia a unidades no convencionales. Por ejemplo, unas tiras de papel se convierten en unidades de medida y de su uso resultarán fracciones (figura 17):

Cuando se incluyen las fracciones como resultado de un reparto, de manera distinta a como se hacía en la propuesta de 1972, los repartos se representan gráficamente, o se pide a los alumnos realizarlos con objetos o dibujos. La página donde se inicia el trabajo con esta interpretación se ve en la figura 18. La página es interesante porque, además de que los repartos se hacen efectivamente, la acción se vincula con la escritura de las fracciones (3 hojas para 4 niños; las 3 hojas se dividen para repartirlas entre los 4 niños; a cada niño le tocan $3 / 4$ de hoja). Esta vinculación (CE-Cl-CTS) también muestra el interés por el significado: aquí de una representación difícil de comprender (la de la forma $a / b)$. 
2 Usa el material recortable número 15 . Con la tira roja mide las otras tiras y completa lo que dicen los niños.

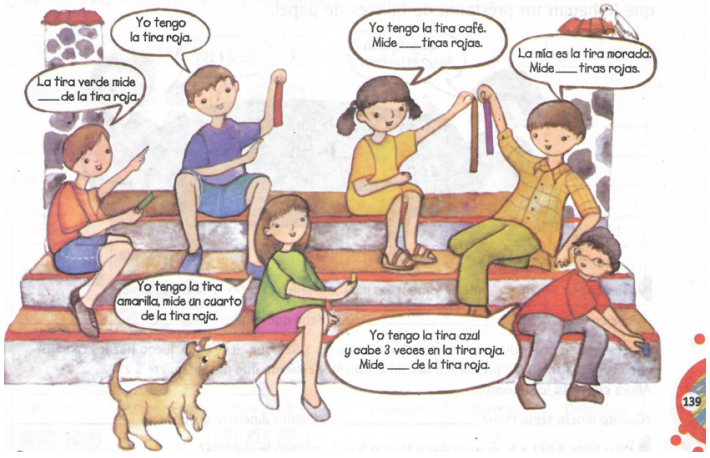

Figura 17. Fragmento de una lección de tercer grado donde las tiras de papel se utilizan como unidades de medida que dan lugar a fracciones.
4 La maestra formó equipos de dos, cuatro y ocho niños. Después entregó algunas hojas a cada equipo para que se las repartieran en partes iguales.
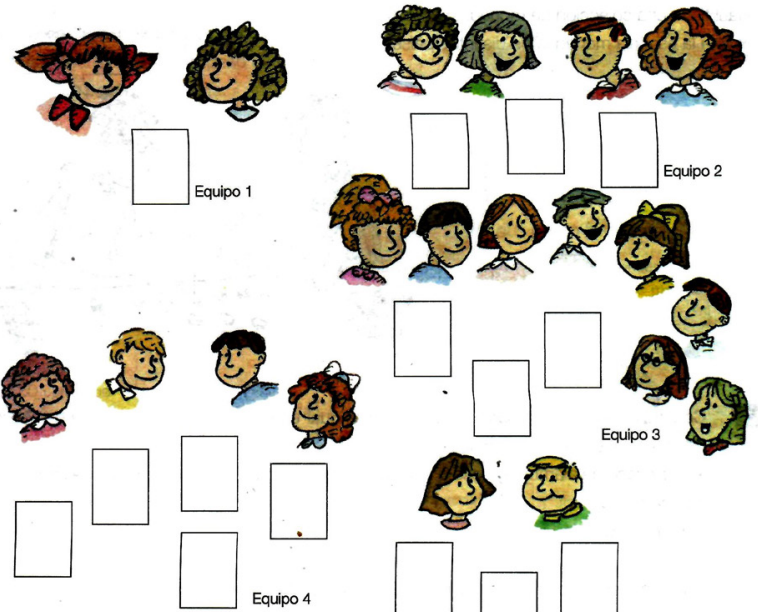

Equipo 4
Figura 18. Lección del libro de cuarto grado donde se introduce la noción de fracción como resultado de un reparto.

Divide los rectángulos para indicar lo que le toca a cada niño en su equipo.

¿Cuántas hojas tiene el equipo 2 ?

¿Entre cuántos niños se repartieron?

¿Cuánto le tocó a cada niño?

Completa los datos que faltan en la siguiente tabla.

\begin{tabular}{|c|c|c|c|}
\hline Equipo & Hojas & Niños & A cada niño le tocó \\
\hline 1 & & & \\
\hline 2 & & & \\
\hline 3 & & & \\
\hline 4 & & & \\
\hline 5 & 3 & 2 & $1+\frac{1}{2}$ hoja \\
\hline
\end{tabular}


Las hasta aquí expuestas no son todas las ideas sobre las fracciones incorporadas en 1993. En el quinto grado se introduce su representación en la recta numérica y se da un amplio tratamiento a las fracciones decimales y la expresión decimal de las fracciones (SEP, 2002c). También la comparación, equivalencia y suma de fracciones, ocupan un lugar en la propuesta.

\section{Comparación, equivalencia y suma de fracciones}

La noción de equivalencia se vincula a situaciones donde se hacen repartos equivalentes (SEP; 2001b, p. 93-93) o a situaciones en contexto de medición o saltos de animales: por ejemplo, "Un salto de $1 / 2$ metro es igual a un salto de $2 / 4$ de metro" (SEP, 2002b, p. 135). Pero la equivalencia se lleva a otros contextos: en una lección de sexto grado la actividad se ubica en la notación musical: ¿Cuántas corcheas equivalen a una blanca?, ¿Qué parte de una redonda es una corchea?, El nivel TS se introduce solicitando establecer la equivalencia entre una fracción (5/4) y tantas notas blancas, o negras, o corcheas como sean necesarias para completar el tiempo musical anotado (SEP, 2001p. 21). Una tabla de números proporcionales que los estudiantes han de llenar a partir de calcular el listón para varios moños, resulta útil para acercar más al nivel TS e incorporar una formalización local sobre la equivalencia:

I

Seguramente las fracciones que te resultaron en las preguntas anteriores son 5/3 y 10/6. Estas fracciones representan la misma medida y hay varias maneras de comprobar que son equivalentes. (SEP, Sexto grado. 25).

El currículo incluye también la suma de fracciones, que inicia en el tercer grado. En éste se utilizan fracciones de denominador 2 o 4 y a lo largo de todo el ciclo educativo se trabaja con fracciones fácilmente manejables. Se espera que los niños, con sus conocimientos etnomatemáticos y los intuitivos desarrollados en la escuela, desplieguen estrategias personales para calcular. Es por ello que, en vez de comunicarse algún procedimiento formal, lo más frecuente es que se comparen las estrategias de solución y los resultados con los de otros compañeros. Es hasta el final de la secuencia, en el sexto grado, donde se expone un ejemplo (no del 
todo desarrollado) de cómo podrían haber sumado los números mixtos implicados en la resolución de un problema (figura 19) (SEP, 2001, p. 55).

Figura 19. Formalización local del procedimiento para sumar números mixtos.

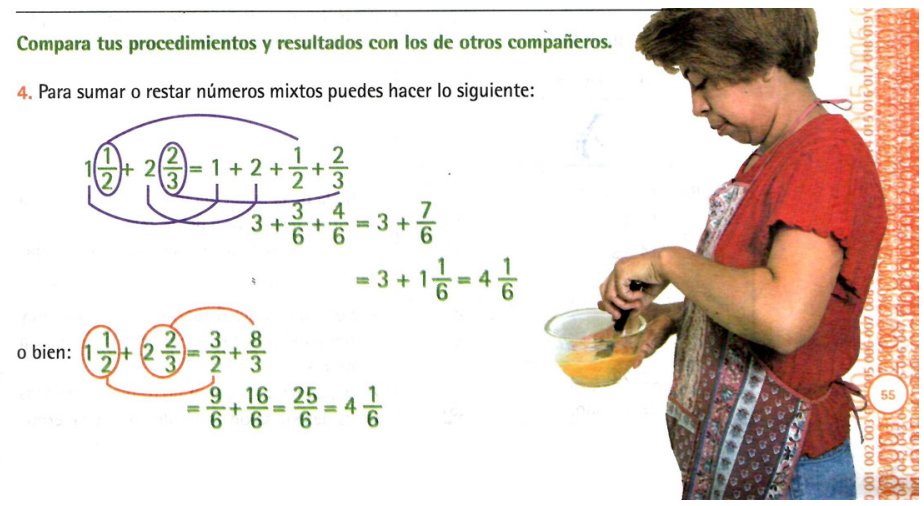

Este tema (la suma de fracciones) culmina en combinación con la idea de equivalencia, mediante una actividad consistente en anotar las fracciones convenientes para lograr el equilibrio entre diversos móviles (figura 20):

Figura 20. Primera página de la lección de sexto grado que cierra el tratamiento de la suma y resta de fracciones.
1. Los móviles son artesanías que se hacen en muchas partes del mundo. El secreto es mantener el equilibrio con los objetos que cuelgan. Anota el número natural o la fracción que se necesita en cada cuadrito vacío para lograr el equilibrio.
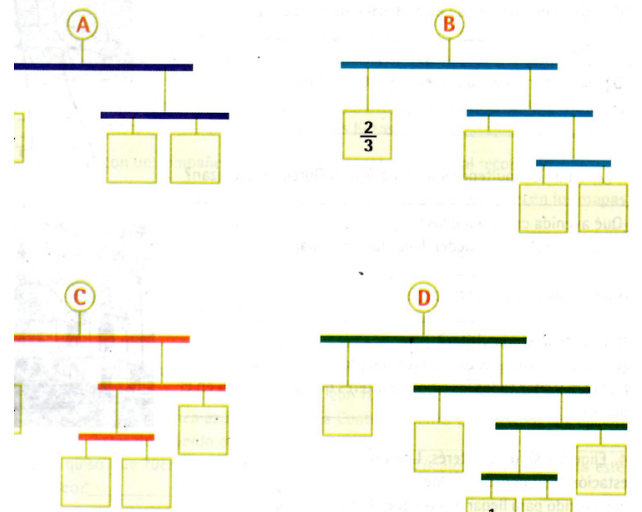

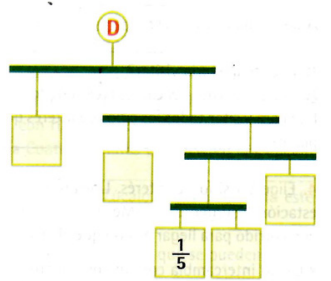


El de los móviles es un ejercicio que obliga a pensar y no sólo a hacer cálculos de modo automático. Es también el final de una secuencia sin alguna formalización procedimental para calcular con las fracciones.

\section{La fracción como razón}

Esta noción tiene un elaborado tratamiento; su inclusión constituye una innovación en la enseñanza de las fracciones. Se inicia en el quinto grado, explicitando que la razón es una forma más de interpretar las fracciones, según subtítulo de la lección "La tienda de pinturas: Fracciones como relaciones o razones" (SEP, 2002c, 142-143). El contexto de mezclas resulta útil para vincular, a partir de situaciones problemáticas, fracciones sencillas (como 5/8) con expresiones del tipo "Litros de pintura blanca por cada litro de pintura verde", o "Fracción de pintura blanca que hay en la mezcla".

Posteriormente la noción se relaciona con la idea "regla de cambio" que -a partir de situaciones problemáticas- se expresa también como "tratos buenos" y "no tan buenos". Por ejemplo, en una lección de sexto grado se plantea: Por cada ficha les doy 3 estampas, Por cada 6 fichas les doy 12 estampas, Les doy una cantidad de estampas igual a dos veces la cantidad de fichas, ¿con cuál regla de cambio creen que ganarán más estampas? (SEP, 2001, pp.30-31).

Los estudiantes han de decidir cuál regla es la que conviene más. En concordancia con el enfoque, se promueve la comparación y discusión de resultados, incluyendo la idea de que "Hay reglas de cambio que son equivalentes porque dan siempre la misma cantidad de estampas" (lección 11, pp. 30-31). Siempre sobre la base de problemas, más adelante se comunica a los estudiantes la posibilidad de representar las "reglas de cambio" o "los tratos" mediante expresiones distintas: a) "por cada tantos...me dan tantos...", b) mediante porcentajes, o c) mediante fracciones (SEP, 2001, p. 45). Hay un notable interés en hacer comprender la noción de razón generando un conocimiento intuitivo sobre esta relación.

Otra vertiente del tema se vincula a las escalas; se inicia mediante indicaciones como: Los lados de la nueva figura deben ser del doble, del triple, etc., sin referencias formales al concepto. Es en la lección 46 (SEP, 2001, p. 104-105) después de varias lecciones que abordan el tema donde se formaliza el concepto de factor de escala: 
El número por el que hay que multiplicar (o dividir) las medidas de una figura para obtener las medidas de la figura a escala se llama factor de escala.

Para que una figura sea una reproducción a escala de otra, el factor de escala debe ser el mismo para todos los lados que se corresponden. Lo anterior equivale a decir que las medidas de una figura deben ser proporcionales a las medidas de la otra. (SEP; 2001, p. 105).

En síntesis, en este currículo hemos visto la incorporación de la fracción asociada al modelo parte-todo de una manera breve y distinta de como se hacía en las propuestas curriculares anteriores. Además, la noción, siempre inmersa en situaciones problemáticas, se presenta vinculada sistemáticamente a las situaciones de medición y de reparto, así como de razón. En el quinto y sexto grados además de un trabajo intenso con la razón, se incluyen nociones afines: porcentaje y escala. Es un claro ensanchamiento de la idea tradicional de fracción.

\section{¿EL SIGNIFICADO OPACÓ AL LENGUAJE?}

El interés por dar significado a las fracciones es notable en esta propuesta. No hay ninguna lección donde la actividad no esté relacionada con alguna representación gráfica de las fracciones o con alguna situación problemática de la que derive la actividad de aprendizaje. Es decir que generar un conocimiento intuitivo (en los términos de Kieren) fue fundamental en este currículo. En cambio, casi no hay formalizaciones en los libros de tercero, cuarto y quinto grado (dos, tres y cuatro respectivamente). En el de sexto grado aumenta el número (a ocho), principalmente en el tema de razón. Pero la prevalencia del conocimiento intuitivo se conservó y no todo lo que hubiera sido conveniente formalizar se formalizó. Llama la atención que los procedimientos para sumar y restar fracciones son motivo sólo de "formalizaciones locales" y no se acompañan de una formalización franca de los procedimientos.

\section{Conclusiones sobre el currículo de 1993}

La interpretación dada al constructivismo en este currículo, llevó a trabajar sistemáticamente los distintos sub-constructos del número racional, y con ello a 
ensanchar el significado de las fracciones. El concepto de fracción (entendida en sentido amplio) se construye con base en la resolución de problemas y ejercicios contextualizados, es muy probable que con ello se impregnara de significado. Pero hay una ausencia importante en esta propuesta: Ios conceptos abordados prácticamente no se formalizan con algún enunciado o definición. Aunque este problema es menor en el sexto grado, siguiendo el pensamiento de Kieren sería válido decir que, en el currículo de 1993, promotor de que los alumnos construyeran las nociones a partir de sus propios recursos intelectuales, el estudio de las fracciones se llevó a cabo, fundamentalmente, en el nivel etnomatemático y en el intuitivo, pero escasamente en el nivel técnico-simbólico.

\section{CONCLUSIONES GENERALES}

En las tres propuestas curriculares revisadas se otorga importancia considerable al concepto de fracción; en todas se desarrollan secuencias de actividades y lecciones que tratan su contenido con amplitud. Empero, la concepción acerca de cómo se aprenden, así como los significados y el lenguaje que se les asocia cambiaron de manera importante en cada una.

El cambio estuvo alimentado por la evolución en las teorías del aprendizaje y el avance de la investigación en educación matemática. De una centración exclusiva en el sub-constructo parte-todo y un enfoque sustentado en principios psicológicos hoy superados, se pasó en 1972 a la incorporación de diversos significados de las fracciones, se amplió el número de sus representaciones destacando el uso de la recta numérica- y se promovió el descubrimiento como vía privilegiada de aprendizaje. Derivado de esto último, se buscó formalizar los conocimientos como corolario de la actividad de descubrimiento, aunque no siempre el intento culminó exitosamente. Como quiera que sea, la promoción del aprendizaje por descubrimiento, el tránsito pausado por el nivel intuitivo, así como la formalización progresiva del lenguaje fueron elementos valiosos incorporados con esta reforma.

La reforma constructivista introducida en 1993 llegó aún más allá y promovió la construcción de los conceptos vinculados a las fracciones a partir de situaciones problemáticas consideradas familiares para los niños. En esta oportunidad, se ve un abandono intencional del esquematismo con que hasta entonces se había tratado el modelo parte-todo, un enriquecimiento de los contextos a los que se asocian las nociones y un amplio reconocimiento a la idea de que 
los niños construyen sus conocimientos mediante la resolución de problemas, la interacción con sus pares y la socialización de las ideas, las estrategias de resolución y los resultados.

Empero, una debilidad de esta propuesta es la escasa formalización de los conocimientos que buscaba comunicar. Me permito utilizar las palabras de Brousseau, para expresar que, para cerrar el círculo que lleva de un conocimiento inicial a un saber se hace indispensable institucionalizar ese saber. El reconocimiento de dicho saber en el edificio del universalmente reconocido hace necesario establecer una definición mediante convenciones lingüísticas y gramaticales aceptadas por una comunidad. (Brousseau, 1986). En términos de Kieren, diríamos que esta propuesta tiene un amplio trabajo en los niveles etnomatemático e intuitivo, y muy escaso en el técnico simbólico.

Para la elaboración de propuestas curriculares futuras, convendrá mirar el pasado de manera crítica, considerar aquello que fue fortaleza, y evitar lo que fue debilidad. Por ejemplo, la reforma de las matemáticas modernas incorporó una importante innovación al intentar que los alumnos descubrieran por sí mismos los conceptos, pero el tratamiento de los distintos significados de la fracción no fue sistemático y el paso por el nivel intuitivo le otorgó demasiada confianza al modelo parte-todo. Igualmente, el constructivismo introducido en 1993, llevó a elaborar una propuesta valiosa para la construcción de la noción de fracción a través de sus diferentes sub-constructos, siempre en situaciones consideradas de interés para los niños. Sin duda fue muy relevante la intención de vincular significativamente a los alumnos con la noción y todas sus implicaciones, pero la falta de formalizaciones debilitó la propuesta.

Hoy en México está en puerta la incorporación de nuevos programas de matemáticas. En la tradición educativa mexicana, cada vez que se emprende una reforma educativa, la ideología de la innovación (Brousseau, 2000) se apodera de los planeadores, quienes evitan mirar hacia atrás, como si la retrospección impidiera generar las condiciones para un mejor aprendizaje. La mejora, según parece, quiere hacerse depender de la innovación. Sin embargo, "al hacer de lo novedoso el criterio esencial para valorar las acciones propuestas, se destruyen las posibilidades de éxito de las mismas, y se muestra al mismo tiempo que no es al mejoramiento de la enseñanza a lo que se aspira". (Brousseau, 2000, p. 31).

En el caso de las fracciones, los exámenes nacionales recientes informan de escasos aprendizajes; también se nos ha informado que en muchas escuelas permanece la centración en el modelo parte-todo y se trabaja muy poco el resto 
de los sub-constructos (Avila, 2006; Izquierdo, 2006, González-Molina 2018). A este tipo de enseñanza, sin duda, también están asociados los resultados que arrojan los exámenes nacionales.

D'Amore y Fandiño (2015), en un interesante escrito publicado en Educación Matemática y titulado "Propuestas metodológicas que constituyeron ilusiones en el proceso de enseñanza de las matemáticas" (p. 7), muestran cómo muchas de ellas tuvieron una gran difusión, pero fueron ilusorias, ya que las mejoras esperadas con su introducción nunca llegaron. Esto parece ser lo que sucede en México con las fracciones.

Es probable, entonces, que sea más útil pensar en cómo mejorar lo que hacen y conocen los profesores y no en incorporar innovaciones que, en palabras de D'Amore y Fandiño, es probable que sólo constituyan ilusiones. Por ello, si bien este escrito tiene por objetivo exponer algunas reflexiones sobre propuestas de enseñanza potencialmente útiles para los diseñadores de proyectos educativos, me pregunto si la lectura de este tipo de análisis podría ser útil para ayudar a los profesores a revisar su práctica. Mi hipótesis es que sí, pero habrá que investigar.

\section{REFERENCIAS BIBLIOGRÁFICAS}

Avila, A. (2006). Transformaciones y costumbres en la matemática escolar. Ciudad de México. México: Paidós. Col. Educador.

Block, D. y Álvarez, A.M. (1999). Los números en primer grado: cuatro generaciones de situaciones didácticas. Educación Matemática. (11)1 57-76.

Block, D. y Waldegg, G. (cords.) (1995). Matemáticas. En: Waldegg, G. Procesos de Enseñanza y Aprendizaje II. Col. La investigación educativa en los ochentas, perspectivas para los noventas. pp. 21-130. Ciudad de México. México. Consejo Mexicano de Investigación Educativa/Fundación SNTE para la Cultura el Maestro Mexicano.

Brousseau, G. (2000). Educación y didáctica de las matemáticas. Educación Matemática. (12)1, 5-38.

Brousseau, G. (1986). Théorisation des phénomènes d'enseinement des mathématiques. Thèse pour obtenir le grade de Docteur d'État Es Sciences. Université de Bordeaux I. France.

Cedillo-Osornio, J.L. (2016). El concepto de equivalencia de fracciones en la educación primaria mexicana entre 1960 y 2011. Tesis de maestría en Desarrollo Educativo no publicada. Ciudad de México. México: Universidad Pedagógica Nacional. 
Charalambous, C.Y. (2007). Developping and testing a scale for measuring students' understanding of fractions. Proceedings of PME 31, 2, 105-112.

Charalambous, C.Y. y Pitta-Pantazzi, D. (2005). Revisiting a theoretical model on fractions: Implications for testing and research. Proceedings of PME 29, 2, 233-240

Cortina, J.L., Zúñiga, C. y Visnovska J. (2013). La equipartición como obstáculo didáctico en la enseñanza de las fracciones: Educación Matemática. (25)2, 7- 29.

Davydov, V.V. y Tsvetkovich, ZH. (1991). On the objective origin of the concept of fractions. Focus on Learning Problems on Mathematics. 13(1), 13-64.

D'Amore, B. y Fandiño, M.I. (2015). Propuestas metodológicas que constituyeron ilusiones en el proceso de enseñanza de la matemática. Educación Matemática. (27)3, 7-43.

Fandiño, M.I. (2009). Las fracciones: aspectos conceptuales y didácticos. Bogotá. Colombia: Editorial Magisterio.

Freudenthal, H. (1983). Didactical Phenomenology of Mathematical Structures. Dordrecht: Reidel. [Fenomenología didáctica de las estructuras matemáticas] Traducción de Luis Puig (2001). En Varios Autores. Textos seleccionados de Educación Matemática. Cd. de México. México: Cinvestav.

González-Molina, I. (2018). Praxeologías matemáticas presentes en los libros y las libretas de alumnos de sexto grado y primero de secundaria. Tesis de doctorado en Educación. México. Universidad Pedagógica Nacional.

Gorostiza, L. y Rivaud, J.J., (coords.) (1974). Matemáticas cuarto grado. Libro del maestro. México. Secretaría de Educación Pública - Comisión Nacional de los Libros de Texto Gratuitos.

Hart, K. (General editor). (1981). Children Undetstanding of Mathematics: 11-16. Eastbourne. England: Anthony Rowe Publishing Services.

Instituto Nacional para la Evaluación de la Educación (INEE). Bases de datos Excale. Recuperado de www.inee.edu.mx el 15 de abril de 2017

Instituto Nacional para la Evaluación de la Educación (2017). Plan Nacional para la Evaluación de los Aprendizajes (PLANEA). Resultados nacionales 2015.Sexto de primaria y tercero de secundaria. México. INEE. Recuperado de www.inee.edu.mx el 5 de febrero de 2018

Izquierdo, G. (2006). Las representaciones sociales de 12 profesores de educación primaria sobre las fracciones y su enseñanza. Tesis de maestría en Desarrollo Educativo no publicada. México: Universidad Pedagógica Nacional. .

Kieren, T.E. (1999) Language used in embodied action and interaction in knowing fractions". En: F. Hitt y M. Santos (Eds) Proceedings of the PME NA XXI. Vol. I, 110-125.

Kieren, T.E. (1988). Personal Knoweldge of Rational Numbers: Its Intuitive and Formal Development. En: J. Hiebert \& M. Behr (Eds.), Number concepts and Operations on 
the Mlddle Grades. (pp. 162-181). EUA: Lawrence Erlbaum Associates/National Council of Teachers of Mathematics.

Kerslake, D. (1986). Fractions: Children's errors and strategies. Windsor, England: NFER-Nelson

Llinares, S. (2003). Fracciones, decimales y razón. Desde la relación parte-todo al razonamiento proporcional. En C. Chamorro (coord.) Didáctica de las matemáticas para Primaria. (pp. 188-220). Madrid: Síntesis.

Llinares, S. y Sánchez, V. (2000). Fracciones. Madrid: Síntesis.

Real, R., Gómez, B. y Figueras, O. (2013). Aspectos de la fracción en los modelos de enseñanza: el caso de un libro de texto. Épsilon. Revista de educación matemática. 30(3), núm. 85, 21-36.

Zazkis, R. y Mamolo, A. (2018). On Numbers: Concepts, Operations and Estructure. En: A. Gutiérrez, G.C. Leder y P. Boero: The second handbook of Research on the Psychology of Mathematics Education. 39-71. Rotterdam/Boston/Taipei. Sense Publishers.

\section{LIBROS Y MATERIALES ANALIZADOS}

Imaz, C. (Coord). (1977). Matemáticas. Primer grado. Libro del maestro (6a ed.). México: Secretaría de Educación Pública-Comisión Nacional de los Libros de Texto Gratuitos.

Secretaría de Educación Pública (SEP). (1960a). Mi cuaderno de trabajo de primer año. Aritmética y Geometría y Estudio de la Naturaleza. México: Conaliteg.

Secretaría de Educación Pública (SEP). (1960b). Mi cuaderno de trabajo de tercer año. Aritmética y Geometría y Estudio de la Naturaleza. México: Conaliteg.

Secretaría de Educación Pública (SEP). (1961). Mi cuaderno de trabajo de quinto año. Aritmética y Geometría. México: Conaliteg.

Secretaría de Educación Pública (SEP). (1960c). Mi libro de tercer año. Aritmética y Geometría y Estudio de la Naturaleza. México: Conaliteg.

Secretaría de Educación Pública (SEP). (1960d). Mi libro de cuarto año. Aritmética y Geometría. México: Conaliteg.

Secretaría de Educación Pública (SEP). (1961a). Mi libro de quinto año. Aritmética y Geometría. México: Conaliteg.

Secretaría de Educación Pública (SEP). (1970). Mi libro de sexto año. Aritmética y Geometría. Décima edición revisada,México: Conaliteg. 
Secretaría de Educación Pública (SEP). (1968). Mi Libro y Mi Cuaderno de Trabajo de Sexto Año. Instructivo para el Maestro. Conaliteg

Secretaría de Educación Pública (SEP). (1972a). Libro del alumno. Matemáticas. Segundo Grado. México: Conaliteg.

Secretaría de Educación Pública (SEP). (1972b). Libro del alumno. Matemáticas. Tercer Grado. México: Conaliteg.

Secretaría de Educación Pública (SEP). (1975). Libro del alumno. Matemáticas. Cuarto Grado. México: Conaliteg

Secretaría de Educación Pública (SEP). (1972c). Libro del Alumno. Matemáticas. Quinto Grado. México: Conaliteg.

Secretaría de Educación Pública (SEP). (1993). Plan y programas de estudio de educación básica primaria. México: Fernández Editores.

Secretaría de Educación Pública (SEP). (2002a). Matemáticas. Tercer grado. Cuarta edición. México: Conaliteg.

Secretaría de Educación Pública (SEP). (2002b). Matemáticas. Cuarto grado. Cuarta edición. México: Conaliteg.

Secretaría de Educación Pública (SEP). (2002c). Matemáticas. Quinto grado. Cuarta edición. México: Conaliteg.

Secretaría de Educación Pública (SEP). (2001). Matemáticas. Sexto grado. Segunda edición. México: Conaliteg.

ALICIA AVILA

Domicilio postal: Guty Cárdenas 121-B, Colonia Guadalupe Inn, C.P. 01020, Alcaldía Álvaro Obregón.

Ciudad de México 